\title{
MOTIVAÇÃO REFLETINDO NA QUALIDADE E PRODUTIVIDADE
}

\section{MOTIVATION REFLECTING ON QUALITY AND PRODUCTIVITY}

\author{
Cristiane Fernanda Sato, Cinthia Bitencourt Spricigo
}

\author{
Pontifícia Universidade Católica do Paraná, Centro de Ciências Exatas e de \\ Tecnologia, Curso de Pós Graduação Lato Sensu em Gestão da Qualidade na Produção de \\ Alimentos, Medicamentos e Cosméticos, Rua Imaculada Conceição, 1155, Prado Velho, \\ CEP 80215-901 - Curitiba - PR \\ RECEBIDO: 12/02/08 ACEITO:05/03/08
}

\begin{abstract}
RESUMO:
Nos tempos atuais, cada vez mais as pesquisas comprovam que funcionários não são máquinas que apenas obedecem aos comandos sem questionar ou falhar. A percepção de que funcionários são pessoas inteligentes, com pensamentos, conhecimento e emoções vêm modificando conceitos no mundo empresarial. Muitas empresas que já adotaram este conceito estão investindo em seus funcionários, o maior bem que possuem. Maior bem pelo fato de serem portadores de conhecimento que ninguém pode tirar. Sem o conhecimento não há como adquirir experiência e sabedoria para driblar a concorrência, ganhando clientes em qualidade de tempo e produto, além de ganho na produtividade. Para tanto, é necessário um fator: a motivação. Funcionários motivados produzem mais e melhor. Têm mais idéias e sentem-se importantes para a organização, sabem que seus superiores confiam neles. A motivação é difícil de se alcançar e muito fácil de se perder. Um simples gesto ou olhar é o que basta para muitos se sentirem desmotivados. Neste contexto, o presente artigo tem como objetivo realizar um levantamento bibliográfico e promover uma discussão sobre como uma organização pode utilizar a motivação dos funcionários como aliada, resultando em incremento da qualidade de produtos e serviços, além de aumento da produtividade.
\end{abstract}

Palavras-chave: Motivação; Produtividade; Qualidade.

\begin{abstract}
:
In present time, more and more researches corroborate the fact that employees are not machines that only obey to commands without questioning or failing. The perception that employees are intelligent people, with thoughts, knowledge and emotions has been changing concepts in the business world. Many organizations that are already engaged on that perception are investing on their employees, who are their most important belonging, for their knowledge. Without knowledge, there is no way to get experience and wisdom to overcome the competitors and to gain clients with product and time quality, besides productivity gains. In order to accomplish all of that, one factor is necessary: motivation. Motivated employees produce more and better, have more ideas, feel important to the organization and know that their superiors trust them. Motivation is something hard to get and very easy to lose. A simple gesture or look is enough to get rid of someone's motivation. In this context, the present work has the aim to bring a bibliographical search and to promote a discussion about how an organization can use their employee's motivation as an ally, resulting in an increase in product and services quality, besides increasing productivity.
\end{abstract}

Keywords: Motivation; Productivity; Quality. 


\section{INTRODUÇÃO}

A motivação significa, motivar a ação, representando então a real necessidade em nosso mundo cotidiano.

No mundo de alta tecnologia em que se vive, a busca por alto rendimento e produtividade é crescente. A exigência de que automóveis tenham alto padrão com motores menores, porém com cada vez maior rendimento, proporcionando maior quilometragem por cada litro de combustível consumido, é um exemplo disso.

Na esfera produtiva das indústrias, a concepção não é diferente. Talvez não se perceba, mas mesmo com a balança comercial das exportações sendo favorável possui-se um índice de importações considerável. Grande parte destas importações é de bens de produção, seja em sistema de informações para melhorar a eficiência do ciclo produtivo, seja em renovação de máquinas industriais para aumentar o volume produtivo, com a diminuição de consumo de energia elétrica e, muitas vezes, até do número de funcionários no chão de fábrica.

Toda essa busca incessante por melhor produtividade e qualidade, são exemplos de situações em que se aplicam meios físicos ou comodites. A questão é: será que é possível aplicar a mesma idéia na busca de qualidade e produtividade quando se trata de pessoas no mundo corporativo? Sim, isto é possível, e a base é a motivação, uma aliada ideal para a busca da qualidade e produtividade no meio humano profissional. Mas a análise de algumas questões e exemplos da vida real é necessária para saber corretamente como agir.

TORRES (2001) repassa dados de 2001 em que o Brasil faturou, entre Janeiro e Outubro, 608,17 dólares por cada tonelada exportada para o Japão. No entanto, pagou 4.247,79 dólares por cada tonelada importada. Perdeu 3.639,62 dólares por tonelada comercializada. O motivo foi exportar produtos com baixo teor de conhecimento como o minério, matériasprimas, chips e equipamentos. O conhecimento para medir, analisar e melhorar a produtividade e para criar está nas pessoas, em seus cérebros. Este é o investimento que as organizações deveriam fazer. Para inovar precisam de conhecimento, e, sem inovação, dificilmente sobreviverão ao mundo competitivo de hoje.

Para Blecker (2005) uma das características de uma empresa inovadora é cultivar um clima de liberdade em que funcionários sentem-se à vontade para expressar suas opiniões a respeito de novos projetos, aprendendo com seus próprios erros.

ABRANTES (2001) defende a idéia de que dar liberdade de expressão gera motivação e que pessoas motivadas trabalham melhor, resultando em produtos de qualidade e melhorando a produtividade. O clima e a cultura organizacional podem levantar a motivação de seus colaboradores. Os seres humanos necessitam de um estímulo externo para incentivar o interno, a motivação vem de dentro de cada um e precisa de incentivo. Cada ser humano busca alcançar seu objetivo, ou seja, sua necessidade. Isto é o que o motiva, desperta e o impulsiona à ação de alcançar o que almeja.

Os grupos de CCQ ,Círculos de Controle da Qualidade, são interessantes no quesito liberdade de expressão, porém devem ser bem trabalhados para não dar liberdade excessiva, permitindo ao funcionário mudar seu setor, conforme seus objetivos e não os da empresa.

Analisando diferentes autores que defendem a motivação como refletora de melhorias na qualidade e produtividade e que funcionários motivados trabalham mais e melhor, este artigo apresentará maneiras de motivar e manter a motivação. 


\section{DESENVOLVIMENTO}

\subsection{Motivação, qualidade e produtividade}

Para Maslow (2000), psicólogo e consultor americano, as necessidades humanas dividem-se em primárias e secundárias, segundo uma hierarquia das necessidades influenciadas por meios internos e externos. As primárias referem-se a fisiológicas, de segurança e estabilidade. As secundárias compreendem necessidades sociais, de estima e de autorealização. Fatores motivadores reproduzem fontes de satisfação como reflexo de sentimentos de realização, crescimento profissional e aceitação de desafios, resultando em aumento da capacidade total de produção.

ABRANTES (2001) faz entender que o que se produz é para agradar o cliente em primeiro lugar, satisfazendo a sua necessidade. Sem ele não há como sobreviver. Qualidade é um quesito fundamental. Qualidade é atender o que o cliente pede, em condições físicas desejáveis, preço e prazo acessíveis. Para isso o produto, seja qual, for deve ser quase sem defeito, deve ser belo aos seus olhos. Ainda mais, não deve causar danos a quem o utiliza e ao meio ambiente. Para conseguir, é preciso pensar também na qualidade de vida no trabalho.

Para Wada (2002), a relação empresa e trabalhador é fundamental para o êxito e objetivos da organização, refletindo significativamente na produtividade. Somente trabalhadores satisfeitos conseguem satisfazer clientes. A organização deverá conhecer seus funcionários, individualmente ou como corpo, para adequar os objetivos da empresa com os dos funcionários. O recrutamento de pessoas certas para cargos certos é muito importante.

TOWNER (1998) diz que, quando um funcionário está desmotivado ou estressado devido à falta de qualidade de vida no trabalho, ele tenta se refugiar em atestados médicos, ou em falta de eficácia, que resultará em desmotivação de outros funcionários. O ciclo segue da seguinte maneira: Na ausência ou ineficácia de um funcionário, outros talvez precisem fazer hora extra, recebendo mais pressão a fim de atender à programação estabelecida. Mais pressão pode ocasionar mais estresse, o que diminuirá a eficácia do funcionário e isto refletirá na qualidade de seu serviço. Conseqüentemente, a produtividade será afetada. Pode-se perceber facilmente se há desmotivação pelo número de atestados médicos e de turnover (rotatividade de funcionários).

CHAVES (2006a) cita estudos realizados pelo psicólogo Mihaly Csikszentmihalyi da Universidade de Chicago, que o fizeram compreender que as pessoas sentem-se motivadas quando há desafios em que podem se superar e mostrar a sua capacidade.

ABRANTES (2001) defende a idéia de que, primeiramente, é preciso entender que produtividade é a relação entre faturamento e custos, sendo que faturamento representa o montante arrecadado com a venda de produtos e serviços. Também se pode defini-la como capacidade de agregar valor em relação a bens e serviços utilizados nos processos produtivos. Produtividade não significa trabalhar mais.

Neste sentido, a qualidade aparece como fator determinante. O motivo deve-se ao fato de que um produto ou serviço sem qualidade quase não vende, se não

vende, não fatura, não faturando restam apenas os custos de fabricação não compensados. Ou seja, prejuízos e não produtividade. Para saber se há produtividade é preciso medi-la por tabelas e gráficos. Para isso é preciso treinar e capacitar pessoas para aquisição de conhecimento para fornecer dados corretos. Uma das maneiras de melhorar a produtividade é utilizar o conhecimento para desenvolver técnicas melhores de produção. Quanto mais produtiva, mais competitiva será a organização. Hoje é crucial ter qualidade em produtos e serviços, além de estrutura física capaz e domínio da tecnologia. 
SOARES (2004) explica que o Brasil, segundo dados do Banco Mundial, é o penúltimo em qualidade de leis trabalhistas. Observando que o brasileiro é criativo e empreendedor, existe um grande potencial desperdiçado que poderia ser mais bem utilizado pelas organizações. Seria um grande impulso para a economia.

Segundo The Economist (2004) o crescimento da produtividade pode indicar o crescimento da economia por conduzir a renda real, inflação, juros, lucros e preços das ações. Importante é não confundir produtividade com produção.

\subsection{Como motivar o funcionário}

Segundo Abrantes (2001), analisando-se a pirâmide de Maslow, as pessoas são motivadas por desejos classificados em uma hierarquia de prioridades. Cada nível alcançado as impulsiona a atingir o próximo, e assim, subseqüentemente. Para Frederick Herzberg a motivação divide-se em dois fatores: aqueles que produzem satisfação e os higiênicos. $\mathrm{Na}$ satisfação encontram-se a realização, reconhecimento, responsabilidade e progresso. Os fatores higiênicos ou que evitam a insatisfação representam segurança, status, dinheiro e condições de trabalho. Porém talvez não atinjam a satisfação. Críticos não concordam com Herzberg pelo fato de ele igualar as pessoas, mesmo sabendo que todas são diferentes e que o fator motivacional para uma pode desmotivar outra. $E$ também por não avaliar a relação entre satisfação e produtividade. Após uma longa pesquisa, o consultor holandês Geert Hofstede descobriu que a pirâmide definida por Maslow não se adequa a todas as culturas, pelo fato de haver diferença na maneira como enxergam as necessidades de cada indivíduo.

Como exemplo, Nelson (1996) explica que as necessidades de pessoas de Primeiro Mundo são diferentes das de Terceiro Mundo, ou então os níveis culturais e intelectuais.

Assim como diz Abrantes (2001), percebe-se que não se pode generalizar a maneira de motivar. É preciso usar táticas diferenciadas, conhecer cada indivíduo ou grupo dentro da empresa. Analisando a situação, parece impossível conhecer cada membro da organização. Mas é possível conseguí-lo contando com a ajuda de supervisores e gerentes, que têm a obrigação de saber como sua equipe se comporta em determinadas situações. Assim, tornase mais fácil estudar maneiras de motivá-la. Existem várias maneiras de reconhecer o trabalho das pessoas, motivando-as, basta saber o que as tornam vencedoras ou perdedoras. O líder é um facilitador dos objetivos da empresa, portanto deve saber como usar os funcionários a favor dela.

Em seu livro, Mirshawka (1988) explica que, no passado, o dinheiro era usado pelos executivos como única maneira de motivar. Analisando as décadas posteriores, os valores monetários revelaram-se menos importantes que outras formas de incentivo. Porém, ainda é a forma mais usada. Hoje, o dinheiro pode representar um impulso, porém, a motivação logo desaparece.

CHAVES (2006d) explica que, para a maioria das pessoas, a recompensa monetária é um incentivo momentâneo, logo, não o motiva porque outras necessidades não foram sanadas, como, por exemplo, as condições de trabalho insatisfatórias. O que falta para um pode não ser o que falta a outro. Com o dinheiro recompensa-se, mas com o reconhecimento toca-se o coração.

Para Abrantes (2001) quando as necessidades básicas são sanadas, o desejo é alcançar a realização pessoal. Ter o reconhecimento do trabalho, ganhar a atenção de outros, saber que seu trabalho é significativo para a organização. Justiça e equidade são fatores importantes na hora de recompensar. Por isso é necessário conhecer a equipe de trabalho. Muitas vezes é necessário mudar conceitos arraigados para alcançar o objetivo da empresa, que é obter um produto de qualidade com produtividade. Mas mudar as pessoas é uma tarefa 
complicada, ainda mais se tratando de suas características humanas. Para conseguir, é preciso tocar o coração delas.

MÖLLER (1997) explica porque é tão difícil motivar algumas pessoas. Por exemplo, se ela tem um trabalho de baixo status, salário ruim, rotineiro ou desinteressante, seria muito difícil prová-la o contrário e motivá-la, mesmo que corra o perigo de ser demitida. A melhor maneira é ensiná-la a orgulhar-se do que faz. O pior seria se não o tivesse! Pensar de maneira positiva facilita a vida.

Existem várias formas de recompensar as pessoas. Grandes Profissionais, (2006a):

a) Plano de cargos e salários:

Ajuda na estruturação e união da empresa; define atribuições de cada cargo e setor; estabelece hierarquização justa; proporciona equilíbrio interno nos valores e salários; extingue cargos desnecessários; cria condições de estímulo e reconhecimento profissional; capta, mantém e descobre talentos internos necessários ao desempenho crescente da empresa.

b) Remuneração variável:

A crescente onda mundial é o estímulo através da Participação de Lucros e Resultados (PLR), que traz motivação para os funcionários gerando atrativos financeiros. Incrementa o comprometimento das pessoas com a produtividade, qualidade e competitividade da organização.

c) Bônus e Programas de sugestões:

A implantação de programas da qualidade é um exemplo vívido de como o bem estar do funcionário colabora com a eficácia do trabalho. Por exemplo, no programa $8 \mathrm{~S}$ existem sensos que obrigam a organização a observar considerações pouco constantes. Um exemplo é a consideração ergonômica. Segundo ela, em todos os setores são feitos estudos a fim de facilitar o trabalho para qualquer descrição física das pessoas, adaptando-se a estrutura física da empresa a estaturas baixas, altas, magras demais, gordas demais com o objetivo de segurança. Com segurança dificilmente haverá acidentes. Um ambiente organizado, limpo, ergonômico e seguro deixa o trabalho mais agradável, resultando em benefícios para a empresa.

d) Viagens:

CHAVES (2006d) dá idéias de recompensas como uma viagem para outra unidade da empresa a fim de conhecer ou apresentar suas idéias ou apresentar suas idéias em um congresso. É uma forma de reconhecimento ao maior número de pessoas possível.

e) CAMPOS (1992) mostra também o GQT:

Gestão da Qualidade total (no estilo japonês), muito eficiente em motivar pessoas por envolvê-las com a organização. Delega o controle a todas as pessoas para satisfação de todas. Todos os níveis são envolvidos, tudo para atender com qualidade o cliente, sem esquecer da produtividade. O GQT melhora a produtividade em longo prazo por investir nos elementos humanos portadores de conhecimento.

CHAVES (2006c) aponta que os CCQ, Círculos de Controle da Qualidade, são eficientes no incentivo ao funcionário. Nestes círculos os colaboradores envolvem-se com os problemas encontrados e buscam soluções. Os resultados obtidos pelos círculos contribuem para uma revolução silenciosa no ambiente de trabalho. A motivação vem junto com o reconhecimento dado aos colaboradores como pessoas capazes e maduras de reconhecer onde poderá haver melhorias e intervir quando ao seu alcance junto com a chefia imediata. Passam por adversidades e usam sua criatividade na busca de soluções, reduzindo custos e aumentando a produtividade. $O$ alcance dos Círculos vai além do ambiente de trabalho e chega até projetos de ação pessoal. Até mesmo da comunidade em trabalhos voluntários. 
Quanto mais pessoas participarem do CCQ o nível de saúde mental da organização pode ser elevado a um nível mais alto. Quanto mais pessoas participarem, melhor será para a organização. A confiabilidade e a capacidade de gerar riquezas também aumenta. Para exemplo, em média o retorno de uma empresa que investe nestas equipes é de no mínimo cinco vezes sobre o capital investido. Por ser espontâneo o grupo tem liberdade para buscar o que lhe dá prazer, ou seja, buscar soluções para problemas cotidianos no ambiente de trabalho e o reconhecimento de seus colegas e superiores, sem fugir das metas da empresa. Esta realização contribui para o crescimento pessoal e para um trabalho agradável por fugir um pouco da rotina do dia-a-dia. Os ganhos relacionados à satisfação do funcionário ainda não podem ser medidos porque não inventaram uma forma precisa de mensurá-lo (CHAVES, 2006a).

Conforme dados de Chaves (2006d), a implantação dos CCQ pode resultar na economia de milhões como nas empresas Multibrás, que economizaram 7 milhões de reais ao longo dos seus 21 anos de programa. CHAVES (2006a) informa, ainda, que empresas como AmBev, Sadia, Embraco, Acesita, CSN, Usiminas Mecânica, Mineração Caraíba, Caraíba Metais, Politeno, Cia Paraibuna de Metais, Cia Mineira de Metais, Santista Alimentos, Springer, Gerdau, Sthil, Weg, entre outras, fazem uso de seus grupos de CCQ ativamente na geração de riqueza.

A Empresa Natura (2006a) também investe no potencial de seus funcionários, envolvendo-os no Movimento Natura, um conjunto de ações que visa conscientização e a mobilização de Consultoras e Consultores para que sejam praticantes das crenças e da visão de mundo Natura. O Movimento busca o equilíbrio entre as questões econômicas e aspectos sócio-ambientais. Faz isso por propor as consultoras a agir, encaminhando pessoas de volta à escola, pela venda de refis e de produtos Crer para Ver. Toda a renda obtida com a venda dos produtos Crer para Ver é destinada à ajuda a pessoas carentes. A empresa possui três selos que identificam o movimento: Nosso Negócio, Nossa Gente e Nosso Planeta. Assim, os consultores são incentivados a serem agentes locais de transformação, com práticas que visam um mundo melhor. O resultado é que o reconhecimento do desempenho das consultoras e consultores passou a levar em consideração também as metas sócio-ambientais, além das metas de vendas. Com relação à responsabilidade corporativa, a empresa foca, além de outros parâmetros, o imenso valor às relações humanas, aperfeiçoando-as com respeito, transparência e ética.

A empresa possui, ainda, o Programa Qualidade de Vida. Objetivando promover a realização profissional, a integração social e familiar e a boa saúde dos colaboradores, é formado por um conjunto de programas educativos, políticas, benefícios e oportunidades de lazer. Para saúde emocional, há o Clube Natura com 16 mil metros quadrados, cercado de florestas com atividades planejadas para o bem-estar dos colaboradores. NATURA (2006c).

Para Möller (1997), hoje o rápido progresso exige grande capacidade de competição das organizações e seus indivíduos. Cada vez mais aumentam cobranças exaustivas de postura e talentos que às vezes podem parecem além do limite de capacidade. Não bastam apenas investimentos em treinamentos se hão houver estímulos. Apenas treinar e não dar subsídio ao trabalho há desmotivação e logo o funcionário pedirá demissão e trabalhará para a concorrência. A prioridade é pessoas certas nos lugares certos, liderança empreendedora capaz de motivar e estimular suas equipes e atingir o alvo.

ABRANTES (2001) esclarece que, devido aos constantes avanços tecnológicos e aos métodos de gestão pela qualidade exigirem a participação efetiva de "todos" os funcionários envolvidos na resolução dos problemas da empresa, faz-se necessário usar o poder da motivação. O comprometimento com a qualidade, depende do grau de motivação presente intrinsecamente em cada indivíduo. Nenhum programa implantado e implementado seguirá 
em frente sem que os envolvidos estejam animados, empolgados com o resultado. Desta forma, todos ficam por dentro do objetivo da empresa e são incentivados a contribuir para o alcance deste. Quando o funcionário recebe uma designação de serviço de modo respeitoso e percebe a confiança deportada a ele, sua motivação e auto-estima são significativamente elevadas porque ele sente-se bem. Ele está recebendo atenção de seu superior. O envolvimento do funcionário nas metas da organização o faz sentir-se importante e facilitará sua determinação e responsabilidade para com ela. A pessoa tem que estar emocionalmente envolvida e saber que também pode sair ganhando para dar o melhor de si. A motivação parte do exemplo da liderança. Suas ordens e tarefas devem ser explanadas de maneira clara e objetiva. Quando cumpridas com eficácia deve-se recompensar os envolvidos. Reuniões longas e sem tomadas de decisões não combinam. Elas devem ser planejadas, marcadas com antecedência com os assuntos, data, horário e local definidos. Assim todos terão tempo para organizar seu tempo estar presente. Decididas as metas e atingidas, os envolvidos devem ser elogiados. A repreensão jamais deverá ser feita em público. Confiança e respeito são importantes. Transmita confiança a sua equipe.

MARTINSKI (2002) diz que, ao surgirem problemas, abordar de maneira sistemática procurando as causas a serem investigadas e não as pessoas causadoras, é sábio. Constrangimentos e humilhações são extremamente desmotivadores. O problema, mesmo que indesejável, deve ser visto como uma fonte de aprendizado e melhoria e não como oportunidade para repreensão em massa.

Para Abrantes (2001), o bom líder é também bom ouvinte. Consegue obediência não por imposição, mas por cultivar a vontade de sua equipe. Ele não age precipitadamente, procura ouvir seus colaboradores além de investigar se há satisfação no trabalho. Como fazer isso? Estimulando o surgimento de idéias, deixando os funcionários à vontade para manifestá-las gerando um Brainstorm, não descartando nenhuma idéia, mas avaliando os prós e contras de acordo com a meta a atingir. O descarte imediato de idéias desmotivará os funcionários e eles raramente darão uma sugestão novamente. Motivar é muito difícil, ao passo que desmotivar é muito fácil: para algumas pessoas basta um olhar ou um gesto. A organização precisa estar ciente de que o progresso da pessoa é possível, mas a regressão também é. Forças que tendem à regressão são: salário menor que o suficiente para sobrevivência ou ameaçadora a esta, ansiedade, medo, mentiras, desconfiança, desilusões, desonestidade, valores. Estes são fatores que dificultam encontrar o equilíbrio entre as forças positivas e negativas. Mesmo com mudanças no estilo gerencial, as organizações devem pressupor que uma certa parcela não irá responder da maneira esperada.

O Dr. Ishikawa (1986) comparou as organizações orientais com as ocidentais e viu uma grande diferença no gerenciamento. Nas empresas japonesas os funcionários são considerados quase membros da família, investindo-se muito neles com grande zelo e afinco, e o emprego é vitalício. No Japão a correta implantação do programa TQC* (Total Quality Control) nas empresas, reduziu o número de funcionários responsáveis pelo controle de qualidade a no máximo $1 \%$, entretanto nos Estados Unidos este número atinge $15 \%$ do quadro de funcionários em uma área de produção.

\section{* O termo TQC foi substituído em 1996 por TQM (Total Quality Management)}

Isto se deve à falta de confiança no ser humano, no lado Ocidental, necessitando de constante inspeção de seu serviço. No Oriente isto não acontece devido ao relacionamento de confiança entre membros da empresa. Williams Eduard Deming diz que a administração ocidental é destruída pela incapacidade de compreender as 
pessoas. (2001):

Mais algumas formas de motivar as pessoas são apresentadas a seguir. ABRANTES

As metas estabelecidas devem ser tangíveis e o grupo ciente da possibilidade de alcançá-las, bem como dos riscos envolvidos. Pressões podem aumentar estes ricos significativamente. As metas devem ser compatíveis com a capacidade competitiva da empresa. Os resultados devem ser divulgados e compartilhados em todos os níveis da organização. Dispondo desta maneira, haverá maior facilidade de cooperação.

"Sim, emergências e rapidez de decisões podem ocorrer, mas não devem tornar-se rotina. Planos bem elaborados e com alto investimento financeiro podem ser fracassados por grupos desmotivados.

" O maior bem que uma empresa possui são as pessoas. Deve-se investir nelas, incentivando a educação para atribuir conhecimento e aumentar o treinamento, favorecendo a produtividade. As pessoas são a essência das organizações, quando se sentem envolvidas na atividade, beneficiam a organização.

"Melhorar constantemente o sistema de produção e serviço a fim de melhorar a qualidade e produtividade reduzindo custos.

MÖLLER (1997) compara a organização a um time de futebol em relação ao bom exemplo de sucesso empresarial. Todos estão empenhados pelo mesmo objetivo, a vitória. Quando o time ganha, todos ganham, se o time perde, todos perdem. Porque o jogador acredita que está em uma equipe, e se ela ganha, todos ganham. As empresas devem ensinar isto aos funcionários para haver mais motivação e espírito de equipe. Um grande exemplo disso é a empresa britânica British Airways. Em meados da década de 80 Margaret Thatcher (na época primeira ministra da Inglaterra) disse: "Vocês agora estão por sua conta. Não receberão mais nenhum subsídio e terão de ser uma empresa rentável no futuro". Realmente no começo não foi fácil, 18.000 pessoas perderam seu emprego. Mas implantaram um projeto "Colocando as pessoas em primeiro lugar". Este projeto envolveu todos da empresa como uma grande família. Esta tarefa seria bem difícil, pois participariam dos seminários faxineiros, responsáveis pelas refeições, gerentes e todos outros setores. Com isso foi descoberto que as pessoas trabalhavam na mesmo empresa, mas não se conheciam. Ensinou-se o conceito de cliente interno de que não é possível atender o externo se os internos, outros departamentos, não são atendidos.

Criado por Möller (1997), O programa "Um dia na vida de British Airways", um evento aberto onde os funcionários e suas famílias participavam conhecendo como a empresa funciona. Acompanharam o trabalho de um engenheiro de vôo e outras atividades relacionadas ao bom funcionamento da empresa. Após este dia todos compreendiam o que acontecia dentro da empresa, e a importância do trabalho em equipe.

Vêem-se muitos gerentes apoiarem treinamentos dizendo que são muito importantes, mas não participam deles. Sempre falta tempo. Se o gerente não dá o exemplo, quem dará?

Conforme Möller (1997) conta, na British Airways o gerente cancelou reuniões com a rainha Elizabeth e com o primeiro-ministro para estar presente aos treinamentos e o resultado foi produtivo. Estes e outros fatores mantiveram a empresa na posição de companhia aérea mais rentável de todos os tempos. Ao contrário de muitas empresas que implantam sistemas de gestão da qualidade, a British mantém o ciclo de treinamentos para contínua atualização de seu pessoal. Quando se investe em um treinamento e implantação para melhorias na empresa, este deverá ser constantemente reciclado para que não haja custos absurdos com a implantação do projeto e após não usá-lo. As mudanças devem ser tratadas como uma semente que precisa de atenção dia-após-dia. Antes de implantar deve-se analisar os impactos nas equipes envolvidas. Infelizmente, muitas empresas acham que investir no funcionário significa apenas treiná-lo em atividades técnicas como marketing, informática, técnica de 
vendas, etc. Ninguém dá ênfase à inteligência emocional, pouco se ouve sobre isso. Muitos acabam achando que é tempo perdido, mas para a British Airways representou apenas dois dias de treinamentos e milhões de libras esterlinas resultantes. Na maior parte das empresas latino-americanas os altos executivos vivem e são treinados como nos países de primeiro mundo e os subordinados em terceiro mundo. Assim é mais difícil alcançar objetivos, se todos estivessem no mesmo pensamento, ou que todos acompanhassem os passos dados, seria muito mais fácil. Quando um funcionário não alcança o que o executivo deseja, logo ele é um fracassado e não receberá um empowerment (delegação de poder ou responsabilidade). Isto mostra que ensinar somente a gerência é perda de tempo, pois quem colocará tudo em prática é o funcionário. É preciso analisar empresas e países líderes em qualidade para olhar os erros e consertá-los. Como exemplos, Japão, Alemanha, Suíça, Dinamarca e Suécia, líderes mundiais em qualidade.

Em seu artigo, Calderon (2006) explica que as empresas brasileiras também estão inovando em técnicas de motivação com entrosamento e autoconfiança, desenvolvendo habilidades e competências. Obviamente, o maior desafio é transportar essas qualidades do campo ideal para a prática. Este processo chama-se "metodologia experimental" onde por meio de uma dinâmica de grupo os integrantes fazem analogias entre as dificuldades encontradas em suas atividades para um ambiente diferente, ao ar livre, por exemplo, resgatando conhecimentos já adquiridos. Para uma equipe de marketing pode-se fazer um treinamento com baldes furados e a missão é enchê-los até determinada quantidade e tempo. Se a tarefa for feita devagar, o balde não encherá e o tempo será ultrapassado. A água é o cliente, e, se não trabalhar com agilidade e em tempo e qualidade esperados, sua decepção será certa. Nesta tarefa nada é novidade, apenas o desafio, apresentado com objetivo determinado, mas a equipe lembra o que alegra o cliente e trabalha para isso refletindo nos resultados da dinâmica. Agora a última moda em Nova York entre executivos é tiro ao alvo. Guerras são simuladas com o objetivo de aliviar a tensão e melhorar a disciplina e autocontrole. Já no Brasil, o Horsemanship Mangement a técnica de domar cavalos está se tornando comum. Analisar como os cavalos são domados, seus pontos fracos e o ganho da confiança no domador auxiliam executivos, supervisores e gerentes a perceber como as pessoas agem quando coagidas ou quando confiantes. Conforme o gerente de Recursos Humanos da TIM Sul, Fábio Silveira, quando as pessoas são obrigadas a desafiar seus medos revelam talentos que muitas vezes são despercebidos na empresa. Outras empresas estão praticando rafting para melhorar a motivação. Apostam que este esporte melhora a capacidade de comunicação entre a equipe e a autoconfiança. Também visa o desenvolvimento da capacidade de planejamento, visão estratégica de mercado e técnicas de negociação. O trabalho em grupo integrado gera sinergia e motivação, animando e revigorando para novos desafios. San'anna (2006) escreve que a prática do Rafting estimula o autocontrole, estabilidade em momentos de stress e trabalho em equipe.

CALDERON (2006) alerta que, deve-se escolher o treinamento correto para a equipe, por isso deve-se conhecer suas habilidades, limites, competências e saber claramente qual o objetivo do treinamento. Seria prudente considerar suas condições físicas.

“Motivação é a relação entre desafio e habilidade. Se a habilidade da pessoa é maior que o desafio, gera acomodação. Se o desafio é maior que a habilidade, gera 0 estresse e a ansiedade" (CHAVES, 2006d).

Conforme a pesquisa realizada pela Revista Sondagem Industrial (2005/2006), o primeiro responsável pelo aumento da produtividade nas empresas paranaenses foi o melhor gerenciamento de pessoal, representado por $62,78 \%$ de desempenho frente a outros fatores (Fig. 1). Fator determinante na prova de que muitas empresas estão reconhecendo a importância de ver os funcionários como seres humanos e não de maneira fordista de que funcionários são apenas "mão de obra". 


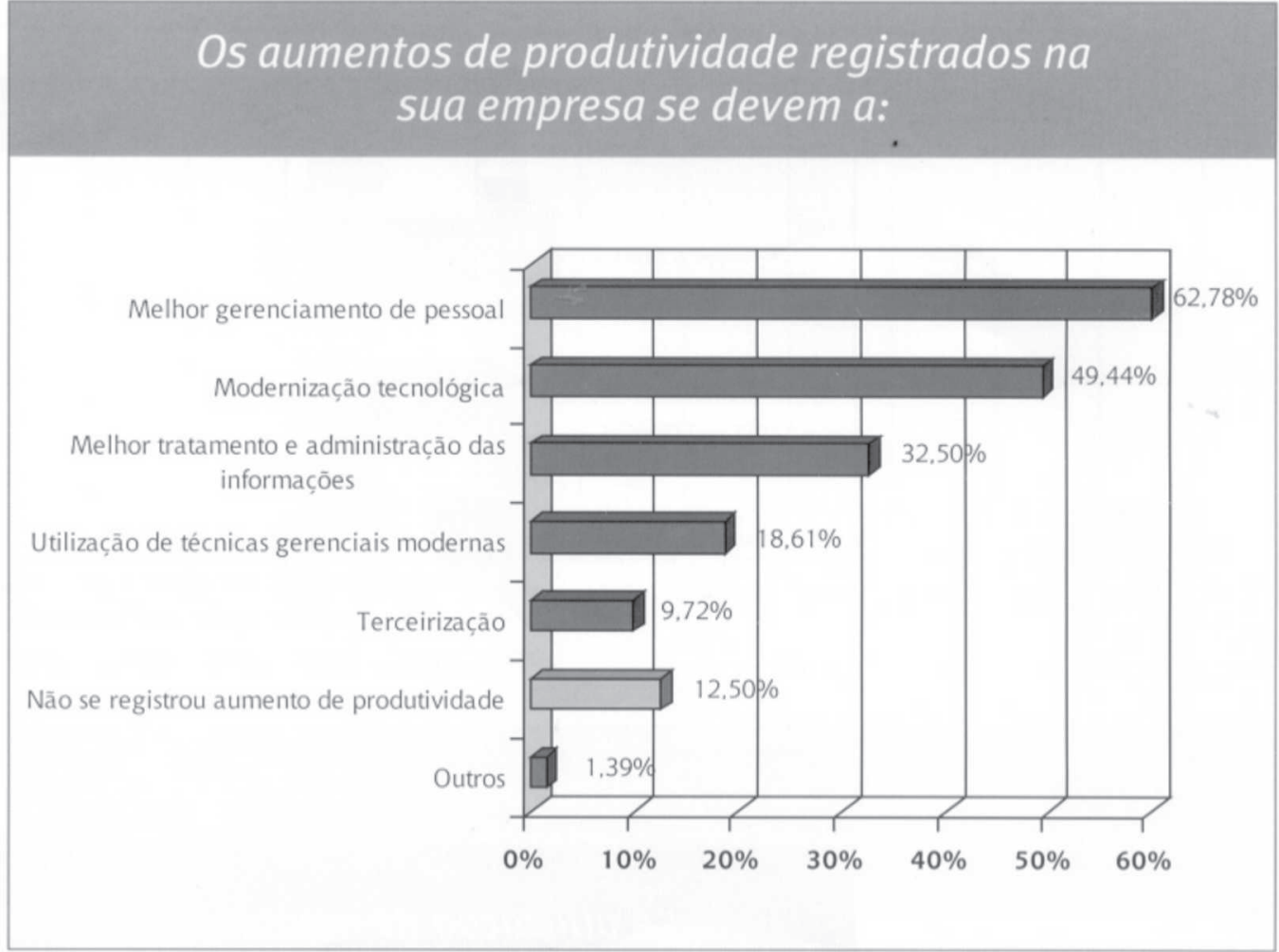

Fonte: Revista Sondagem Industrial

Figura 1 - Fatores relacionados ao aumento de produtividade em empresas paranaenses.

"O melhor gerenciamento de pessoal (62,78\%) e a modernização tecnológica (49,44\%) foram os principais responsáveis pelos aumentos de produtividade"(SONDAGEM INDUSTRIAL, 2005/2006).

\section{CONCLUSÃO}

É preciso reconhecer o valor dos colaboradores dentro da organização, tratando-os de maneira humanitária, seguindo exemplos de empresas que obtiveram sucesso como a Natura, para obter bons resultados. Não encarar como fraqueza conhecer as pessoas, mas, sim, como força para motivar e conseguir alcançar os objetivos organizacionais.

Existem várias formas de recompensar adequadamente, conforme cada situação. $O$ CCQ é uma boa forma de incentivar a participação e demonstrar confiança na equipe, incentiva grandemente a motivação por acreditar no potencial do funcionário que estará motivado por 
um longo período. Quando o funcionário participa ele quer reconhecimento, ser recompensado. O reconhecimento não é esquecido, esta é a grande vantagem. Encarar as pessoas como bens da empresa ajudará a melhorar a relação empresa-trabalhador, fortalecendo a confiança e a motivação da equipe, bem como o aumento da produtividade e da qualidade.

\section{REFERÊNCIAS}

ABRANTES, José. Programa 8S - A base da filosofia seis sigma- Editora Interciência: Rio de Janeiro, 2001, $169 \mathrm{p}$.

BLECHER, Nelson. Idéias que viram dinheiro. EXAME, São Paulo, edição 856, n.23, p 22-28 , nov/2005.

CALDERON, Cynthia. Treinamentos Inusitados. Observatório da Indústria, Curitiba, Ano 03 - № 10 jan/fev 2006.

CAMPOS, Vicente Falconi. Controle da Qualidade Total, editora,1992.

CHAVES, Neusa Maria. CCQ - Alternativa para Geração de Riqueza Coletiva. INDG. Disponível em: <http://www.indg.com.br/emc/textos/texto4.asp> Acesso em: 26 abr. 2006a.

CHAVES, Neusa Maria. CCQ - O CCQ é uma ferramenta valiosa para funcionários

interessados em mostrar seu potencial. INDG. Disponível em: <http://www.indg.com.br/emc/ textos/texto12.asp> Acesso em: 26 abr. 2006b.

CHAVES, Neusa Maria. CCQ - Uma "revolução silenciosa" nos ambientes de trabalho. INDG. Disponível em: <http://www.indg.com.br/emc/textos/texto10.asp> . Acesso em: 26 abr. 2006c.

CHAVES, Neusa Maria.. CCQ - Vida Exectiva. INDG. Disponível em: <http://www.indg.com.br/ idg/vidaexecutiva.asp>. Acesso em: 26 abr. 2006d.

GRANDES PROFISSIONAIS. Política Cargos e Salários. Disponível em http:// www.grandesprofissionais.com.br/html/rh/política_cargos_salarios.htm. Acesso em $21 \mathrm{fev}$. $2006 a$

ISHIKAWA, Kaoru. TQC - Total Quality Control - Estratégia e Administração da Qualidade. São Paulo: IMC International Sistemas Educativos, 1986.

MARTINSKI, Aurélio. Problemas e culpados. Folha de Londrina, Londrina, 11 mar. 2002. Caderno Economia, Espaço IBQP-PR, p3. Disponível em: <http://www.ibqp.org.br/artigos.php>. Acessível em 21 fev. 2006.

MASLOW, Abraham H. Maslow no gerenciamento, Rio de janeiro: Qualitymark Editora, 2000. 
MIRSHAWKA, Victor, 1988 Editora Nobel. Entrosando-se com a qualidade. São Paulo/SP

MÖLLER, Claus. A Qualidade através das pessoas. HSM Management. São Paulo, jul / ago 1997.

NATURA. Movimento Natura. Natura. Disponível em: <http://www.naturanet/web/br/foryale/ hotsites/RC/default.asp>. Acessível em 03 mai. 2006. a

NATURA. Responsabilidade Corporativa. Natura. Disponível em: <http://www.naturanet/web/ br/foryale/hotsites/RC/default.asp>. Acessível em 03 mai. 2006. b

NATURA. Programa Qualidade de Vida. Natura. Disponível em: <http://www.naturanet/web/ br/foryale/hotsites/RC/default.asp>. Acessível em 03 mai. 2006. c

NELSON, Reed e Mauro C.Loureiro, Cultura organizacional vencendo o dragão da resistência , 1996 casa Imagem Editorial.

AN'ANNA, Adriano Lins. Rafting - Espírito de Equipe. Brasil Viagem. Disponível em: $<$ www.brasilviagem.com/material/?CodMateria=29olCodPagina=93>. Acessível em 05 mai. 2006.

SONDAGEM INDUSTRIAL. Curitiba: SEBRAE, 2005. Anual.

SOARES, Lucila. Nadando contra a corrente. IBQP. Disponível em: <http://www.ibqp.org.br/ artigos.php> Acesso em: 21 fev. 2006.

THE ECONOMIST. Revendo a medida de produtividade. Valor Econômico, São Paulo, 12 nov. 2004. Caderno Internacional, p A9. Disponível em: <http://www.ibqp.org.br/artigos.php> Acesso em: 21 fev. 2006.

TOWNER, LASLEY, Controlando o estresse na empresa, Editora Clio , 1998, são Paulo 120 paginas.usadas 18 ao 44,74 ao 84

TORRES, Fulgêncio. Melhorando a produtividade. Folha de Londrina, Londrina, 06 dez.2001. Caderno Economia, Espaço IBQP-PR, 02. Disponível em: <http://www.ibqp.org.br/artigos.php>. Acessível em 21 fev. 2006.

WADA, Haruo. Gestão do trabalho: nova mentalidade. Folha de Londrina, Londrina, 28 jan. 2002. Caderno Economia, Espaço IBQP-PR, p3. Disponível em: <http://www.ibqp.org.br/ artigos.php>. Acessível em 21 fev. 2006. 